Bio - grafía. Escritos sobre la Biología y su Enseñanza. ISSN 2027-1034

Edición Extraordinaria. p.p. 1017 - 1025

Memorias del IX Encuentro Nacional de Experiencias en Enseñanza de la Biología y la Educación Ambiental. IV Congreso Nacional de Investigación en Enseñanza de la Biología.

\title{
INVARIANTES OPERATORIOS QUE ACTIVA UN ESTUDIANTE DEL GRADO QUINTO DE BÁSICA PRIMARIA, A TRAVÉS DE UNA SECUENCIA DE SITUACIONES EXPERIMENT ALES ORIENT AD AS EN LA TEORÍA DE LOS CAMPOS CONCEPTUALES
}

\section{OPERATIONAL INVARIANTS ACTIVATED BY ASTUDENT OF THE FIFTH GRADUATE BASIC PRIMARY, THROUGH A SEQUENCE OF EXPERIMENTAL SITUATIONS ORIENTED IN THE THEORY OF THE CONCEPTUAL FIELDS}

\author{
Herrera López Adriana Carolina, ${ }^{1,2}$ \\ Villa Hurtado Leny Yohana, ${ }^{1,2}$ \\ Cardona Castaño Gloria María ${ }^{3}$
}

\section{RESUMEN}

Este artículo es producto del Trabajo de Grado para optar al título de Licenciado en educación básica con énfasis en ciencias naturales y Educación ambiental Facultad de Educación, Universidad de Antioquia, Medellín. En este se analiza la presencia de los invariantes operatorios de un grupo de estudiantes durante la solución de una secuencia de situaciones experimentales orientadas en la Teoría de los Campos Conceptuales de Gerard Vergnaud. Para ello se llevan a cabo prácticas de laboratorio con los estudiantes del grado quinto de Básica Primaria de una Institución Educativa oficial del municipio de Bello, Antioquia donde se estudian los conceptos célula eucariota y célula procariota. El análisis se realiza en dos fases; en la primera se identifican los invariantes operatorios iniciales de los estudiantes y en la segunda se analiza la evolución conceptual de estos, después de la aplicación de dichas situaciones, donde se obtuvo como resultado un avance significativo por parte de los participantes frente al campo conceptual de referencia.

PALABRAS CLAVE: invariantes operatorios, campos conceptuales, célula eucariota, célula procariota, situación experimental, conocimiento, aprendizaje.

\section{ABSTRACT}

This Article is product of the graduation project made for apply to the degree of "Licenciado en educación básica con énfasis en ciencias naturales y Educación ambiental" from "Universidad de Antioquia", Medellín. This project analyses the presence

\footnotetext{
${ }^{1}$ Licenciadas en educación Básica con Énfasis en Educación Ambiental. Universidad de Antioquia. herrera.carolina262@gmail.com, lenny_86@hotmail.es

${ }^{2}$ Integrante del semillero PiEnCias

${ }^{3}$ Asesora de tesis
} 


\title{
Bio - grafía. Escritos sobre la Biología y su Enseñanza. ISSN 2027-1034
}

\section{Edición Extraordinaria. p.p. 1017 - 1025}

\author{
Memorias del IX Encuentro Nacional de Experiencias en Enseñanza de la Biología y la \\ Educación Ambiental. IV Congreso Nacional de Investigación en Enseñanza de la \\ Biología.
}

of operational invariants in a group of students, while solving a sequence of experimental situations under the eye of the Theary of Conceptual Fields from Gerard Vergnaund. For this, lab practices take place with the students of fifth grade of primary school from an official educational institution in the municipality of Bello, Antioquia where concepts of prokaryotic and eukaryotic cell are studied. The analysis is made in two moments, in the first one, the initial operational invariants are identified and in the second moment it is analyzed the conceptual evolution of this invariants, after the application of the situations exposed before, where the results showed a significant advanced of the participants in front of the conceptual field of reference.

KEY WORDS: operational invariants, conceptual fields, elementary school, eukaryotic cell, prokaryotic cell, experimental situation, knowledge, learning.

\section{PRESENTACIÓN}

Las prácticas de laboratorio son una estrategia importante en los procesos de enseñanza de las Ciencias Naturales, puesto que aportan al desarrollo de habilidades de pensamiento y favorecen la aproximación de los niños al que hacer científico y desarrollo de conceptualizaciones (Andrés \& Pesa, 2004), con lo cual se contribuye a la formación de la mirada crítica que se necesita en el aprendizaje de las ciencias. Pueden exponerse diversos planteamientos sobre la labor de las prácticas experimentales en frente a los aportes en la evolución del conocimiento conceptual, los métodos de aplicación y el desarrollo de destrezas procedimentales. No obstante, en algunas escuelas estas no suelen cumplir un papel relevante, pues se tiende a prevalecer los contenidos teóricos enseñados de manera tradicional en detrimento de la situación experimental, lo que lleva al estudiante a la replicación de conceptos sin ninguna relación con la cotidianidad, dificultando la capacidad analítica argumentativa y la formulación de preguntas e hipótesis que le posibiliten al estudiante acercarse a los resultados esperados en su proceso aprendizaje (Herrera, Villa \& Zapata, 2016).

A partir de la identificación de los factores que impiden que las prácticas de laboratorio tengan un mayor impacto en la enseñanza de las ciencias en la escuela, se hace necesario replantear los métodos bajo los cuales son empleadas, orientándolas hacia una metodología basada en secuencia de situaciones experimentales, donde el estudiante lleve a cabo determinadas acciones que favorezcan la solución de las mismas. Para ello, esta investigación se fundamentó en la teoría de los campos conceptuales de Gerard Vergnaud (1990, 1997, 1998), un "referencial psicológico sobre los procesos de conceptualización en los sujetos que ha sido utilizado en investigaciones sobre aprendizajes científicos" (Cardona, 2014, p. 2). Vergnaud describe el campo conceptual como aquellos problemas y situaciones que implican el uso de diversos tipos de conceptos, procedimientos y representaciones que se encuentran estrechamente relacionados (Moreira, Caballero \& Vergnaud, 2009). 
Bio - grafía. Escritos sobre la Biología y su Enseñanza. ISSN 2027-1034

Edición Extraordinaria. p.p. 1017 - 1025

Memorias del IX Encuentro Nacional de Experiencias en Enseñanza de la Biología y la

Educación Ambiental. IV Congreso Nacional de Investigación en Enseñanza de la Biología.

Se retoman algunos elementos de dicha teoría como los invariantes operatorios, los cuales se encuentran conformados por los conceptos-en-acción y teoremas-en-acción. Estos son componentes esenciales de los esquemas y a su vez, orientadores en los procesos de aprender a aprender las ciencias. Los conceptos-en-acción son "un objeto, un predicado o simplemente una categoría de pensamiento considerada pertinente o relevante para lidiar con una situación" (Vergnaud, 1998, p. 167), es decir son formas complementarias de explicitar una misma estructura cognitiva con diferente grado de dificultad, en cuanto, al teorema-en-acción se estima como una proposición sobre algo real que se considera verdadero, es decir, aquellas frases que el sujeto elabora a partir de sus esquemas para dar respuesta a dicha situación.

Para el caso específico donde se llevó a cabo este estudio se identificó que a pesar de la importancia de las prácticas de laboratorio en la enseñanza de las ciencias en el abordaje de la célula, parecía no generarse una apropiación amplia de las dimensiones de este concepto. Se evidenció que pese a la presencia permanente del tema en los programas, este era asimilado superficialmente dándole mayor relevancia a la información que al desarrollo de las competencias que se pueden adquirir en torno al mismo. De acuerdo a lo anterior la pregunta que orientó esta investigación fue: ¿Qué invariantes operatorios emplea un grupo de estudiantes del grado quinto de Básica primaria de una Institución Educativa oficial, cuando resuelven una secuencia de situaciones experimentales relacionadas con los conceptos de células eucariota y procariota? Para lo cual se tuvo como finalidad analizar los posibles invariantes operatorios que los estudiantes activaban en la solución de dichas situaciones. Adicionalmente se evaluaron los aportes de la teoría de los Campos Conceptuales en los procesos de enseñanza de las ciencias.

\section{METODOLOGÍA}

Esta investigación se realiza con estudiantes del grado quinto de Básica Primaria de una Institución Educativa Oficial, ubicada en el municipio de Bello, donde se retoma como campo conceptual de referencia células eucariota y procariota (Audesirk, Audesirk, \& Byers, 2013), este se elige por ser un tema que pese a ser enseñado en diferentes grados de escolaridad, no se logra una comprensión a profundidad frente al tema (Mengascini, 2006).

La metodología privilegiada en este estudio fue desde un enfoque cualitativo (Hernández, Fernández, \& Baptista, 2006), en el marco de un estudio de caso (Stake, 1999). Para el trabajo de grado se seleccionaron cuatro estudiantes como participantes, este número se estableció de acuerdo al desarrollo de la investigación y a criterios como: ser estudiante de la Institución Educativa, estar cursando grado quinto de básica primaria y tener disposición e interés frente a las actividades propuestas y realizarlas. Sin embargo para este artículo solo se considera un caso, el cual se denomina estudiante E4. 
Bio - grafía. Escritos sobre la Biología y su Enseñanza. ISSN 2027-1034

Edición Extraordinaria. p.p. 1017 - 1025

Memorias del IX Encuentro Nacional de Experiencias en Enseñanza de la Biología y la Educación Ambiental. IV Congreso Nacional de Investigación en Enseñanza de la Biología.

La investigación se realiza en dos fases; en la primera se desarrolla una serie de actividades orientadas a la identificación de los invariantes operatorios iniciales planteados por los estudiantes; en la segunda fase se trabaja en la implementación de una propuesta de enseñanza orientada en tres tipos de situaciones experimentales (tabla 1), a partir de las cuales se analizan los posibles invariantes operatorios que activan los estudiantes en la solución de las tareas planteadas a partir de dichas situaciones. Para lo que se proponen una serie de conceptos, proposiciones, representaciones y procedimientos que debe poner en función el estudiante.

Tabla 1. Propuesta de enseñanza

\begin{tabular}{|c|c|c|}
\hline Tipo de situación & Situación experimental & $\begin{array}{l}\text { Algunas preguntas propuestas a } \\
\text { partir de la situación experimental. }\end{array}$ \\
\hline $\begin{array}{l}\text { S1: Reconocimiento } \\
\text { de los procesos de } \\
\text { las células que } \\
\text { hacen posible el } \\
\text { desarrollo a nivel } \\
\text { reproductivo, } \\
\text { nutricional y de } \\
\text { relación permitiendo } \\
\text { la existencia de los } \\
\text { seres vivos. }\end{array}$ & $\begin{array}{l}\text { Conociendo las funciones } \\
\text { vitales de la Célula } \\
\text { En este laboratorio se resalta } \\
\text { la importancia de las bacterias } \\
\text { en la industria, donde este tipo } \\
\text { de células pone en función sus } \\
\text { principales actividades vitales. } \\
\text { Para ello se les propone a los } \\
\text { estudiantes la elaboración de } \\
\text { un producto de frecuente } \\
\text { consumo: "El yogur". }\end{array}$ & $\begin{array}{l}\text { ¿Por qué no es posible observar a } \\
\text { simple vista los componentes que } \\
\text { convierten la leche en yogur? } \\
\text { ¿Conoces un mecanismo que te permita } \\
\text { visualizar esos componentes? ¿Cuál o } \\
\text { cuáles? } \\
\text { ¿Qué pasaría si sometieras la leche a } \\
\text { componentes como el agua y no a } \\
\text { células bacterianas especializadas en } \\
\text { realizar este proceso? }\end{array}$ \\
\hline $\begin{array}{l}\text { S2: } \\
\text { Análisis de factores } \\
\text { externos que } \\
\text { afectan los procesos } \\
\text { de una célula } \\
\text { alterando su } \\
\text { desarrollo normal }\end{array}$ & $\begin{array}{l}\text { ¿Cómo se pueden afectar } \\
\text { las funciones de la célula? } \\
\text { Durante este laboratorio se } \\
\text { llevaron a cabo tres fases: } \\
\text { construcción del medio de } \\
\text { cultivo, inoculación de } \\
\text { bacterias y control biológico. }\end{array}$ & $\begin{array}{l}\text { ¿Crees que existe alguna manera de } \\
\text { observar algo tan pequeño como las } \\
\text { bacterias sin utilizar microscopio? } \\
\text { Al observar la acción que realiza cada } \\
\text { agente químico sobre el cultivo, se } \\
\text { puede observar que no todos tienen una } \\
\text { reacción de control en las bacterias } \\
\text { ¿Cómo podrías explicar esto? } \\
\text { ¿Cuándo nuestro cuerpo se enferma } \\
\text { debido a la presencia de bacterias, que } \\
\text { tipo de células se encuentran afectadas? }\end{array}$ \\
\hline
\end{tabular}


Bio - grafía. Escritos sobre la Biología y su Enseñanza. ISSN 2027-1034

Edición Extraordinaria. p.p. 1017 - 1025

Memorias del IX Encuentro Nacional de Experiencias en Enseñanza de la Biología y la Educación Ambiental. IV Congreso Nacional de Investigación en Enseñanza de la Biología.

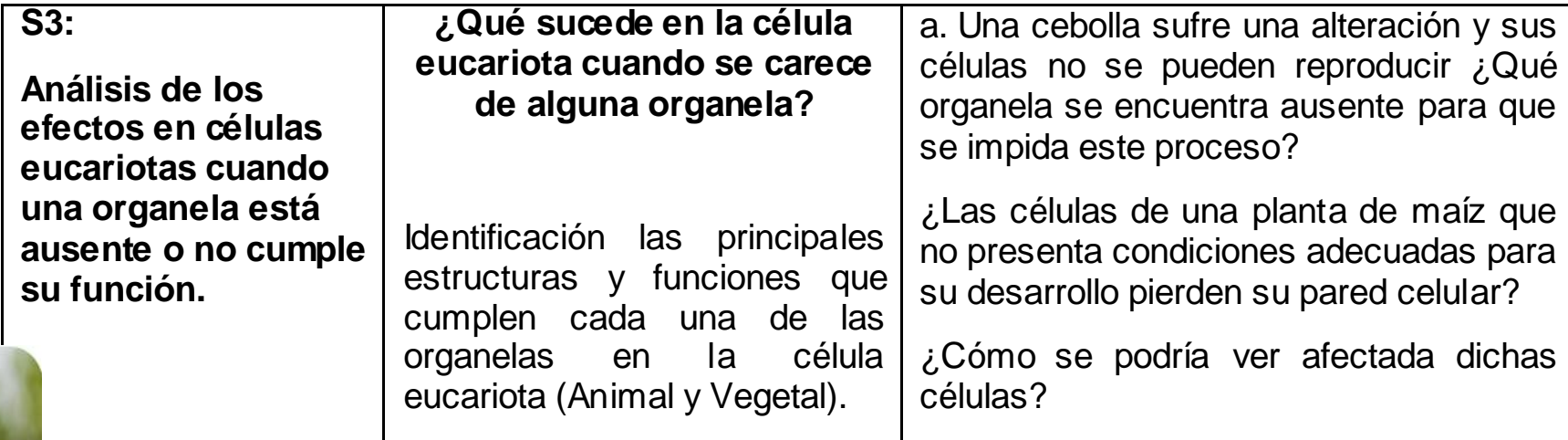

Para la recolección de la información se emplearon técnicas e instrumentos como: la observación, grupo de discusión, mapa conceptual y cuestionario abierto. Posteriormente se analizaron los datos a partir de las siguientes categorías:

Tabla 2. Categorías apriorísticas

\begin{tabular}{|c|c|}
\hline CATEGORIAS & SUBCATEGORIAS \\
\hline \multirow{2}{*}{$\begin{array}{l}\text { 1. Conceptos de células eucariota y } \\
\text { procariota. }\end{array}$} & 1. Funciones y procesos celulares \\
\hline & $\begin{array}{l}\text { 2. Acción de agentes químicos y físicos sobre la } \\
\text { célula. }\end{array}$ \\
\hline
\end{tabular}

\section{ANÁLISIS Y RESULTADOS}

Invariantes operatorios iniciales planteados por el estudiante -primera fase-

A partir de las categorías establecidas y teniendo en cuenta la interpretación de las representaciones iniciales que realiza el estudiante con relación a algunos conceptos de células eucariota y procariota y procesos propios de la experimentación se infiere lo siguiente:

Frente a la categoría Concepto de células eucariotas y procariotas, -subcategoría procesos y funciones celulares- el caso E4 interpretó el concepto de nutrición celular con un bosquejo de célula con algunos puntos que se remiten al alimento que pasa a través de la membrana. En cuanto al proceso de reproducción celular el estudiante ilustró dos células juntas logrando aproximarse a la teoría.

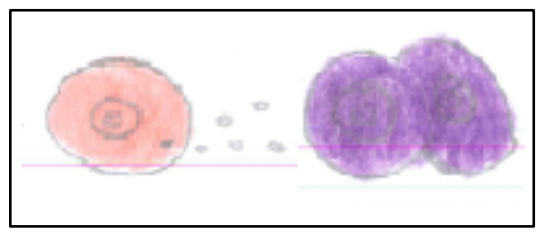

Representación del proceso de nutrición y reproducción celular 
Bio - grafía. Escritos sobre la Biología y su Enseñanza. ISSN 2027-1034

Edición Extraordinaria. p.p. 1017 - 1025

Memorias del IX Encuentro Nacional de Experiencias en Enseñanza de la Biología y la

Educación Ambiental. IV Congreso Nacional de Investigación en Enseñanza de la Biología.

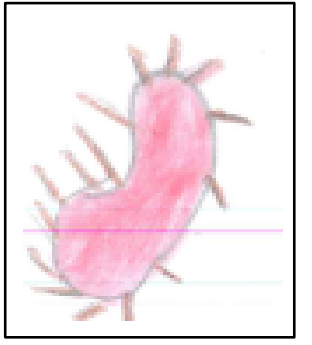

Representación célula eucariota

Con respecto al concepto de célula eucariota, este fue representado mediante un esquema que se asemejaba a una célula procariota. Además, al expresarse verbalmente el estudiante E4 mencionó que "la célula eucariota contiene la célula animal". Al preguntarle "¿qué es una célula eucariota?" expuso que son los animales, dejando de lado otras células que componen este grupo. Cabe resaltar que el estudiante parece no identificar con claridad las estructuras celulares y su funcionalidad, evidenciando un concepto alternativo, al plantear que procariota era una organela

Frente a la subcategoría relacionada con la Acción de agentes químicos y físicos sobre la célula, el estudiante hizo mención a las bacterias sin lograr hacer un vínculo con el concepto de célula procariota. Adicionalmente se remitía a estos microorganismos como factores perjudiciales para la salud y el entorno, sin aludir a los beneficios de estos en la industria. Con relación a la categoría de procedimientos experimentales, E4 no abordó la necesidad del uso del microscopio para observar las células.

De acuerdo con los datos aportados por el estudiante se pudo inferir los siguientes Invariantes Operatorios: -El alimento entra por la membrana de la célula -Las células están dentro del cuerpo -Las células contienen núcleo, citoplasma, mitocondrias, ribosomas, membrana plasmática y procariotas- Las células eucariotas contienen células animales -Las bacterias producen enfermedades.

Con respecto a las acotaciones que realizó el estudiante se pudo inferir en relación a la teoría de los campos conceptuales Las conceptos-en-acción y teoremas-en-acción que designan los conocimientos contenidos en sus esquemas, permitiendo interpretar poca solidez sobre el tema, pues no se activan suficientes invariantes operatorios al enfrentarse a las situaciones propuestas.

\section{Invariantes operatorios planteados por el estudiante -Segunda fase-}

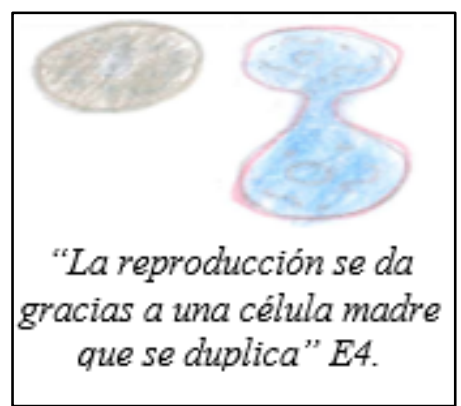

procesos pueden ser alterados, debido a la presencia de agentes físicos y químicos, que impiden el funcionamiento de la célula. Adicionalmente amplió su representación al expresar la existencia de algunas bacterias que se
Al confrontar al participante a las diferentes situaciones y analizando las representaciones que realizó después de la intervención se pudo valorar que el estudiante considera necesario la presencia de diferentes organelas que permitan su funcionamiento normal, reitera la membrana celular y su función en el proceso de nutrición. Además, emplea un nuevo concepto en acción como la presencia de núcleo en la reproducción.

Asimismo el estudiante planteó que estos
Bacteria: "vive por su cuenta, se alimenta y respira. También producen enfermedades $y$ contaminación que se quita con los agentes químicos" E4. 
Bio - grafía. Escritos sobre la Biología y su Enseñanza. ISSN 2027-1034

Edición Extraordinaria. p.p. 1017 - 1025

Memorias del IX Encuentro Nacional de Experiencias en Enseñanza de la Biología y la

Educación Ambiental. IV Congreso Nacional de Investigación en Enseñanza de la Biología.

vuelven resistentes a dichas sustancias, lo que posibilitó deducir que E4 hizo operatorio un nuevo concepto a sus esquemas mentales, que le permitieron realizar una construcción más elaborada como lo propone Vergnaud en su teoría.

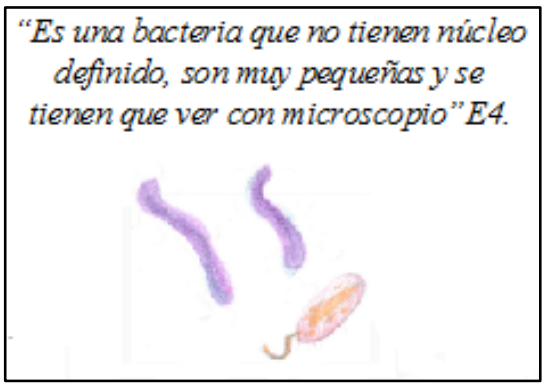

Con relación a la categoría procedimientos experimentales se pudo interpretar que el estudiante comprendía la importancia del uso del microscopio en la observación de las células, introduciendo nuevos conceptos y teoremas en acción en relación al procedimiento para la observación de las células.

A partir de lo anterior se pudo inferir que hubo una evolución frente al campo conceptual de referencia si tenemos en cuenta el contexto donde se desarrolló esta investigación, pues no solo se logró un acercamiento al dominio de los diferentes materiales e instrumentos utilizados en el laboratorio, sino también en las relaciones de conceptos que permitieron fortalecer el vínculo de lo teórico- práctico.

Los posibles invariantes operatorios -conceptos y teoremas en acción-construidos por los estudiantes en esta segunda fase son: -El núcleo es el encargado de la reproducción - Sin el núcleo la célula no se podría reproducir - Los agentes químicos afectan a la célula -Los agentes químicos eliminan las bacterias - Las bacterias se vuelven resistentes a algunos agentes químicos - Las bacterias se pueden ver a través de la formación de colonias en el agar -Para ver las bacterias se debe cortar las muestras y montarlas al portaobjetos y cubreobjetos -Para ver las muestras se agrega el colorante -Las células se observan al microscopio por ser pequeñas.

Con esta investigación se pudo establecer lo que propone la Teoría de los Campos Conceptuales, donde hay un orden en los procesos cognitivos, los cuales se vincularon con la identificación de situaciones, conceptos, proposiciones, representaciones y reglas de acción donde el sujeto participó de forma activa, movilizando los fundamentos de sus esquemas para potenciando los procesos de conceptualización para la evolución cognitiva y el desarrollo de competencias (Castro, 2008) de las ciencias naturales

\section{CONCLUSIONES Y RECOMENDACIONES}

La teoría de Campos Conceptuales como referente teórico encauza la investigación de los aprendizajes logrados en los estudiantes, facilitando un análisis en las implicaciones conceptuales sobre la enseñanza de conceptos científicos relacionados como células eucariota y procariota, mediante el reconocimiento de invariantes operatorios empleados en el momento de resolver preguntas y situaciones problematizadoras.

En relación a la propuesta de enseñanza, los estudiantes lograron elaborar vínculos entre conceptos, establecer jerarquías, semejanzas y diferencias entre éstos, permitiendo observar cuestiones a nivel estructural y de procesos celulares, de los cuales se pueden 
Bio - grafía. Escritos sobre la Biología y su Enseñanza. ISSN 2027-1034

Edición Extraordinaria. p.p. 1017 - 1025

Memorias del IX Encuentro Nacional de Experiencias en Enseñanza de la Biología y la Educación Ambiental. IV Congreso Nacional de Investigación en Enseñanza de la Biología.

deducir interacciones entre los esquemas generados a partir del desarrollo cognitivo de los estudiantes y la búsqueda de solución a diversas situaciones, expresando una acomodación nueva en sus invariantes operatorios.

Este trabajo dejó abiertas algunas preguntas que pueden establecer un aporte importante para futuros procesos investigativos, entre estas destacamos: ¿De qué manera contribuye el desarrollo de prácticas tempranas de laboratorio y el acercamiento con el quehacer científico al sujeto en formación? ¿Cómo un campo conceptual de referencia enseñado mediante el enfoque constructivista acerca al estudiante a un aprendizaje experimental significativo?

\section{BIBLIOGRAFÍA}

- Andrés, M. M., \& Pesa, M. A (2004). Conceptos-en-acción y teoremas-en-acción en un trabajo de laboratorio de física. Recuperado de https://seer.ufmg.br/index.php/rbpec/article/viewFile/2298/1697

- Audesirk. T., Audesirk. G., \& Byers. B. E. (2013). Biología: la vida en la tierra. México: Pearson Educación.

- Cardona, G. M. (2014). Formación de maestros en ciencias naturales: movilización de elementos de sus esquemas. (Tesis inédita de doctorado). Universidad de Burgos, Burgos, España.

- Castro, M. (2008). Resolución de problemas: ideas, tendencias e influencias en España. En: R. Luengo., B. Gómez., M. Camacho., \& L. Blanco., (Eds.). Investigación en educación matemática XII (pp. 113-140). Badajoz: Sociedad Española de Investigación en Educación Matemática.

- Hernández, R., Fernández, C., \& Baptista, P. (2006). Metodología de la investigación. México: McGraw Hill.

- Herrera, A. C., Villa, L. Y., Zapata, D. A. (2016). La enseñanza de las células eucariotas y procariotas mediante una secuencia de situaciones experimentales orientada en la teoría de los campos conceptuales. (Tesis de pregrado). Universidad de Antioquia, Medellín, Colombia.

- Mengascini, A. (2006). Propuesta didáctica y dificultades para el aprendizaje de la organización celular. Revista Eureka sobre Enseñanza y Divulgación de las Ciencias, 3 (3), 485-495.

- Miranda, C. A., \& Andrés, M. M. (2009). El aprendizaje en el laboratorio basado en resolución de problemas reales. Sapiens. Revista Universitaria de Investigación, 10 (2), 181-194. 
Bio - grafía. Escritos sobre la Biología y su Enseñanza. ISSN 2027-1034

Edición Extraordinaria. p.p. 1017 - 1025

Memorias del IX Encuentro Nacional de Experiencias en Enseñanza de la Biología y la Educación Ambiental. IV Congreso Nacional de Investigación en Enseñanza de la Biología.

- Moreira, M. A., Caballero, M. C., \& Vergnaud, G. (2009). La teoría de los campos conceptuales y la enseñanza/aprendizaje de las ciencias. España, Burgos: Servicio de Publicaciones.

- Stake, R. E. (1999). Investigación con estudio de caso. Madrid: Morata.

- Vergnaud, G. (1990). La teoría de los campos conceptuales. Recherches en Didáctique des Mathématiques, 10 (2, 3), 133-170.

- Vergnaud, G. (1997). The nature of mathematical concepts. En: T. Nunes., \& P. Bryant. (Eds.). Learning and teaching mathematics, an international perspective. Hove (East Sussex): Psychology Press Ltd.

- Vergnaud, G. (1998). A comprehensive theory of representation for mathematics education. Journal of Mathematical Behavior, 17 (2), 167-181. 